\title{
EDUCACIÓN
}

\section{El apoyo familiar en el proceso de formación académica en los estudiantes}

\author{
Ninfa González Orrego ${ }^{1}$
}

\begin{abstract}
Resumen
Introducción: Este trabajo se ha realizado en el contexto de la relación familiaescuela, específicamente con el tema del apoyo familiar en el proceso de formación académica y personal. Se centra en las variables de comunicación y participación por parte de los padres durante el proceso educativo de los estudiantes.
\end{abstract}

Objetivo: Diseñar una intervención orientadora y educativa para fortalecer la relación familia - escuela a través de propuestas que sistematicen la formación y la participación de los padres en el proceso académico y personal de sus hijos. Material y Método: Se han utilizado varios procedimientos para detectar la problemática de la participación de la familia en los procesos educativos en un centro educativo privado.

Primeramente, se realizó un análisis de la matriz FODA del centro educativo, remitido vía correo electrónico a través del consejo del centro educativo, en dicho documento se analizaron las amenazas que está atravesando el centro para poder tratar dichas situaciones que afectan a los estudiantes en su proceso académico.

Como segundo instrumento se diseñó un cuestionario con preguntas de carácter cerrado dirigido a los docentes del centro, con el objetivo de constatar el nivel y calidad de apoyo y participación de la familia en la formación académica de sus hijos. Una vez terminado el cuestionario se remitió vía correo electrónico a los docentes del centro educativo.

Cabe mencionar que el cuestionario fue analizado por 2 profesoras paraguayas y por el consejo del centro educativo, además, fue revisado por dos expertos de la Facultad de Educación (UCM) para su mayor fiabilidad y validez.

Como tercer instrumento se analizaron las fichas de los estudiantes, facilitadas por equipo directivo para conocer la cantidad existente de cada tipo de familia en el centro.

Resultados: Por los datos disponibles del centro educativo y por el cuestionario realizado, se refleja la considerable falta de acompañamiento de la familia en

\footnotetext{
1. Universidad Complutense de Madrid.

El trabajo corresponde al Trabajo Final del Máster en la Universidad Complutense de Madrid.

E-mail: ninfaorrego7@gmail.com
}

DOI: 10.26885/rcei.foro.2018.74 


\section{Apoyo familiar en el proceso de formación académica en los estudiantes. González Orrego}

el proceso de enseñanza-aprendizaje, así como falencias en la comunicación, lo cual hace pensar en un impacto negativo en el desarrollo personal y social de los educandos.

Conclusiones: Diseñar un proyecto de intervención orientadora para lograr la participación y el acompañamiento de todos los padres en la educación de los hijos durante el proceso escolar; para lo cual se planearon dos programas con varias actividades que puedan ayudar a mejorar la comunicación de las familias. Dichos programas son la plataforma virtual y la escuela para familias diseñados para atender a los diversos tipos de familia que se encuentran en los centros educativos. En estos programas hay espacios y materiales de apoyo motivadores que impulsan a participar a los padres en la formación personal y social de sus hijos.

Se espera que con la aplicación de estos programas se logre mayor interacción entre familias y profesores, padres e hijos, profesores y alumnos, mediante el trabajo colaborativo y cooperativo. Esta interacción conjunta previsiblemente traerá consecuencias positivas para los estudiantes del Centro Educativo y en Sí para toda la comunidad educativa.

Es importante destacar que gracias a la tecnología interactiva se puede potenciar un aprendizaje de calidad. Siempre que se utilice adecuadamente la tecnología ofrece muchas posibilidades a la orientación educativa, sobre todo si pensamos en familias que, por ejemplo, disponen de poco tiempo para acercarse al centro escolar o que se hallan en otros países.

Que, en medio de tantos avances tecnológicos, en medio de tantas posibilidades de comunicación no perdamos la conexión principal y fundamental entre la familia y la escuela.

Palabras clave: apoyo familiar, acompañamiento, relación familia-escuela.

\section{RefERencias}

Alfonso, C. (2003). La participación de los padres y madres en la escuela. Barcelona. Graó.

Cano González, R., Castillo Arredondo, S., Casado González, M., Pedro, A. \& Ceinos Sanz, C. (2013). Contextos de intervención de la orientación educativa: la familia. En R. C. González (Ed.), Orientación y Tutoría con el alumnado y las familias (p. 235). Madrid: Biblioteca Nueva, S.L.

Ladrón de Guevara, C. (2000). Condiciones sociales y familiares y fracaso escolar. El fracaso escolar. Madrid: Doce Calles.

Martinez-Otero, V. (2016). Orientacion Personal y Familiar. Madrid: CCS.

Miguel, C. R. (2001). Factores familiares vinculados al bajo rendimiento. Revista complutense de educación, 12(1), 81. 